\title{
Reducing the Length of Stay in Oncological Surgical Patients: Impact of Early Hospitalist Co-Management
}

\author{
Ana Ludimila E Cancela ${ }^{1}$, Manoel Carlos B Souza ${ }^{1}$, Marcon C A Lima ${ }^{1}$, Pedro Caruso ${ }^{2}$ and Ramon T Costa ${ }^{2 *}$ \\ ${ }^{1}$ Hospital Medicine Division, AC Camargo Cancer Center, Brazil \\ ${ }^{2}$ Intensive Care Department, AC Camargo Cancer Center, Brazil
}

Submission: June 11, 2018; Published: August 15, 2018

*Corresponding author: Ramon T Costa, Intensive Care Department, AC Camargo Cancer Center, Brazil; Email: ludicancela@gmail.com

\begin{abstract}
Hospital Medicine care dedicated to cancer patients has grown in recent years. The presence of hospitalists in the co-management of surgical patients has been associated with decreasing Length of Stay (LOS). This study aims to evaluate the impact of hospitalist team co-management on length of stay in an oncological surgical population. This is a retrospective analyze of the patients assisted by the Hospitalist Team from 2013 through 2016. The primary outcome was the Average Length of Stay (ALOS). The time from admission to the first hospitalist evaluation was significantly smaller in the group with a LOS less than 16 days $(\mathrm{p}<0.0001)$ and the inverse relationship was also true: the LOS was higher in the group evaluated by the hospitalist for the first time only after 3 days from admission (Late co-management) $(\mathrm{p}<0.0001)$. Early Hospital Medicine team co-management of cancer surgical patients is associated with lower LOS.
\end{abstract}

Keywords: Hospital medicine; Hospitalist; Oncologic surgery; co-management; Length of stay

Abbreviations: LOS: Length of Stay; ALOS: Average Length of Stay

\section{Introduction}

Hospital Medicine is a specialty (Hospitalist) dedicated to the care of acutely ill patients and experienced remarkable growth in high-income countries during the recent decades [1-3]. However, it is still incipient in most middle-income countries just like Brazil.

The Hospitalist care for surgical patients has been associated with decreased Length of Stay (LOS) [4-6], readmission rate [5] and hospital mortality [7]. Although there are hospitalists at cancer centers all over the world, there is a lack of data about the effect of the co-management of oncological surgical patients by hospitalists [8].

The aim of this study was to analyze the impact of an early hospitalist evaluation at the LOS of oncological surgical patients from a tertiary oncological center in a middle-income country.

\section{Material and Methods}

We conducted an observational retrospective study in cancer patients assisted by the Hospital Medicine Department in a 480 beds Cancer Center in Brazil between January 2013 and December 2016. Data were retrieved from a prospectively collected database. We included a total of 4695 patients that were evaluated by the Hospitalist Department in the study period. The following clinical data were included: number of patients, age, Average Length of Stay (ALOS) and time from hospital admission to the beginning of co-management by a hospitalist. Linear regression was used to compare the ALOS during the study period. The surgical patients were divided in two groups according to the time from hospital admission to the first evaluation of the hospitalist team: early comanagement group (time to first evaluation $\leq 3$ days) vs late comanagement group (time to first evaluation $>3$ days). Age was described as mean \pm standard deviation and mean age between groups were compared using the t-student test. Non-parametric variables were described as median (25-75\% percentile). We used the Mann-Whitney test to analyze the non-parametric variables. The median hospital LOS (16 days) for the surgical population was used as the cutoff value to build a Kaplan-Meier curve considering a LOS higher than 16 days (high LOS) as endpoint. The primary outcome was the hospital length of stay (LOS) of the patients evaluated. P-values $<.05$ were considered to indicate statistical significance.

\section{Results}

During the study period, 4695 patients were evaluated by the Hospital it team. Mean age was $68.4 \pm 13.0$ years. As seen in Table 1 , the total number of patients assisted by the team increased from 1037 in 2013 to 1245 in 2016 (+20.0\%). Proportionally, the number of clinical patients managed only by the hospitalists increased significantly, from a total of 461 patients in 2013 (44.4\% of all patients) to 576 in 2016 (46.3\% of all patients), an absolute increase of $24.9 \%$, while the number of co-managed patients remained stable (576 in 2013 and in 2016). The pelvic surgery department, urology and colorectal surgery, was responsible for the greater proportion of co-management between the several subspecialties (Table 1). 
Table 1: Total number of patients, ALOS and percentage of patients by surgical subspecialty.

\begin{tabular}{|c|c|c|c|c|}
\hline Variables & $\mathbf{2 0 1 3}$ & $\mathbf{2 0 1 4}$ & $\mathbf{2 0 1 5}$ & $\mathbf{2 0 1 6}$ \\
\hline Total Number of Patients & 1037 & 1219 & 1194 & 1245 \\
\hline Co-management (n, \% of all patients) & $576(55.5)$ & $544(44.6)$ & $573(47.9)$ & $576(46.3)$ \\
\hline Clinical patients (n, \% of all patients) & $461(44.5)$ & $675(55.4)$ & $621(52.1)$ & $669(53.7)$ \\
\hline ALOS & 18.8 colocar DP & 18.3 colocar DP & 17.1 colocar DP & 15.9 colocar DP \\
\hline ALOS clinical patients & 13.7 colocar DP & 13.7 colocar DP & 11.76 colocar DP & 11 colocar DP \\
\hline ALOS surgical patients & 23.3 colocar DP & 25.5 colocar DP & 23.04 colocar DP & 21.8 colocar DP \\
\hline Colorectal and Urology & Co-managed patients (by specialty) (n, \%) & $221(40.6)$ & $214(37.3)$ & $221(38.4)$ \\
\hline Upper GastrointestinaI surgery & $226(39.2)$ & $103(18.9)$ & $127(22.2)$ & $114(19.8)$ \\
\hline Head and Neck surgery & $149(25.9)$ & $60(11.0)$ & $76(13.2)$ & $72(12.5)$ \\
\hline Oncologic Ginecology & $67(11.6)$ & $36(6.9)$ & $35(6.1)$ & $27(4.7)$ \\
\hline Ortopedics & $62(10.7)$ & $36(6.6)$ & $20(3.5)$ & $24(4.2)$ \\
\hline Other & $22(3.8)$ & $88(16.1)$ & $101(17.6)$ & $118(20.5)$ \\
\hline
\end{tabular}

LOS = length of sty.

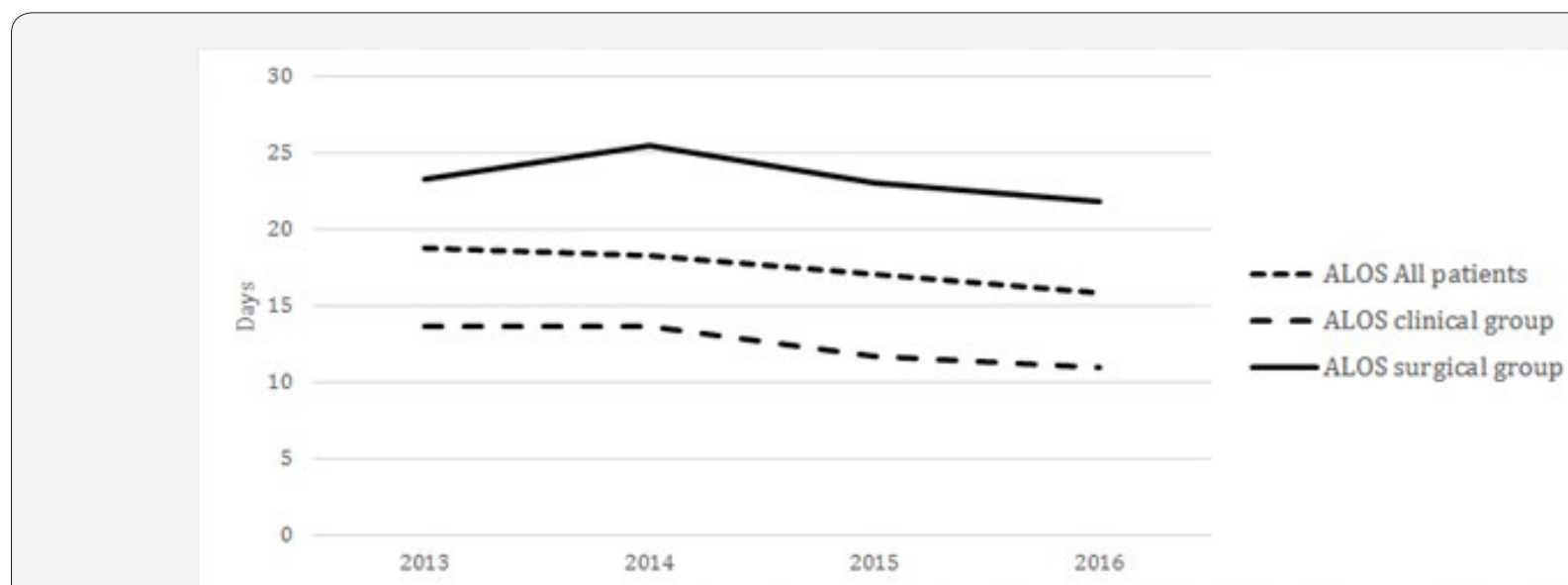

Figure 1: Average Length of Stay (ALOS) evolution in days during the study period.

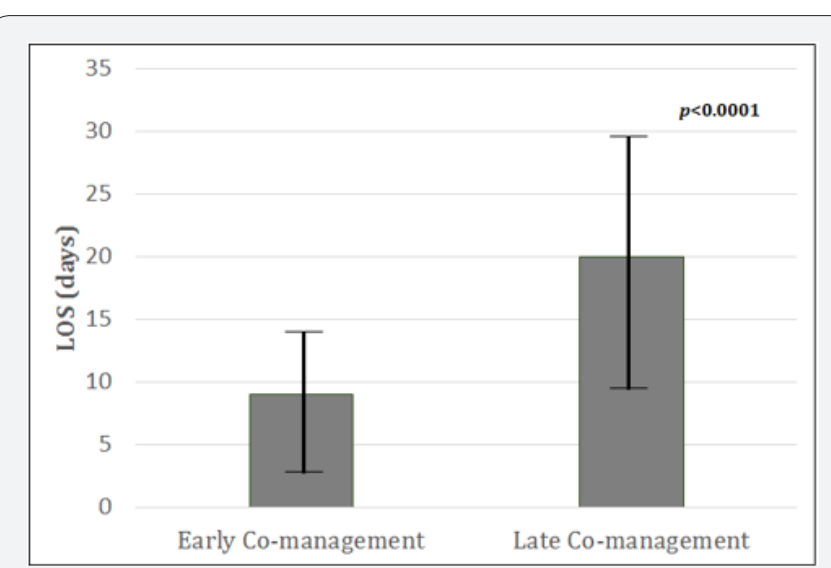

Figure 2: Length of Stay in the early and late co-management groups.

${ }^{*}$ Values expressed as medians and interquarile ranges.

The ALOS decreased progressively both in the clinical group (from a media of 13.7 to 11 days, a reduction of $19.7 \%$ ) and in the surgical (co-management) group (from a media of 23.3 (to 21.8 days) (Figure 1). Linear regression showed this decrease to be statistically significant for both the surgical (beta -0.094 ; CI -2.958,-1.149; $\mathrm{p}<0.0001$ ) and clinical groups (beta -0.145 ; CI $-1.952,-1.116$; $\mathrm{p}<0.0001$ ) A total of 2249 surgical patients were comanaged by the Hospitalist team during this period. The median time from admission to the first hospitalist evaluation was 5 days (2-10, $25-75 \%$ percentiles). The LOS was significantly higher (20 days; $12-35,25-75 \%$ percentiles) in those patients who initiated the co-management after 3 days from hospital admission (late comanagement) than in the early co-management group (9 days; $5-18,25-75 \%$ percentiles $)(p<0.0001)$ (Figure 2$)$. Age was similar in both early and late co-management groups $(69.1 \pm 11.4$ vs $68.0 \pm$ 13.8 years; $\mathrm{p}=0.06$ ).

We used the median LOS (16 days, 9-29, 25-75\% percentiles) as the cutoff value to analyze the impact of the time to first hospitalist evaluation at the LOS. Patients with a LOS greater than 16 days were considered the High LOS group. Curiously, age was lower in the High LOS group than in the group with a LOS less than 16 days (66.4 \pm 14.5 vs $70.4 \pm 10.32$ years; $\mathrm{p}<0.001$ ). The Kaplan-Meier probability curve (Figure 3 ) showed that the early co-management group had a lower probability of staying longer in the hospital. 


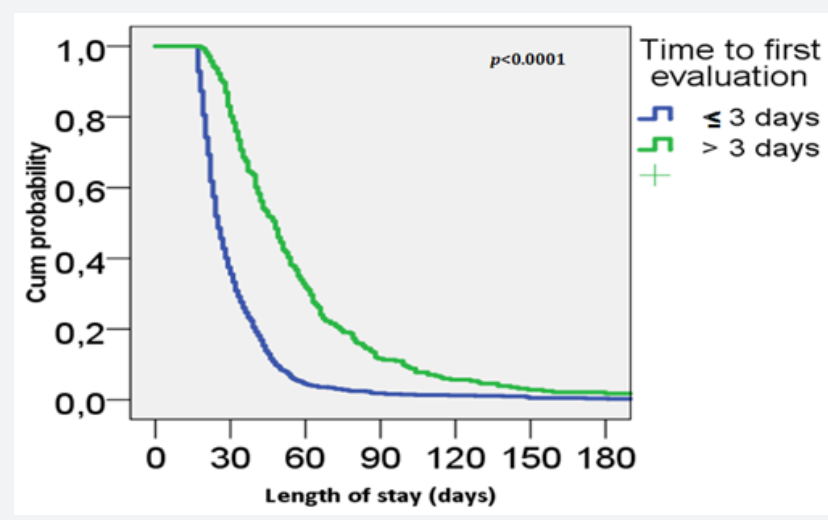

Figure 3: Probability of a High Length of Stay (>16 days) in the Early vs Late co-management.

\section{Discussion}

Although there are evidences of the impact of a co-management by a hospitalist on the LOS of surgical patients, the knowledge is limited about this clinical care in oncological surgical patients. Bracey et al. [4] found that the implementation of a hospitalistorthopedic co-management program reduced the LOS by 1.6 days in older patients [4]. Rohatgi et al. [5] in a large study involving more than 16000 surgical patients demonstrated that the co-managed group had a lower probability of staying at the hospital longer than 5 days $[5,6]$.

Our data showed a progressive reduction of the LOS through the years since the beginning of co-management by the hospitalist team. There was an improvement of communication with the surgical specialties, management of hospitalized patients and adaptation to the routine of an oncologic service by the hospitalist team.

The average LOS varies according to the type of procedure considered. Pucciarelli et al. [9] analysed 75280 patients submitted to cancer colorectal procedures and the median LOS was 13 days [9], while Nassour et al. [10] reported a median LOS of 11.5 days for robotic and 11.8 days for laparoscopic pancreaticoduodenectomy [10]. Our higher ALOS when compared to the literature is probably a consequence of the complexity of our co-managed patients: oncological surgical patients with high risk procedures and their possible complications, prolonged recovery and multiple medical comorbidities. In general and colorectal cancer patients, only 35.2 and $27.6 \%$ respectively were co-managed by a hospitalist or internal medicine physician. In both populations the comanaged patients were older, had more comorbidities and more postoperative complications than the group managed only by the surgeons $[11,12]$.

In our study there was an association between the time of the first hospitalist evaluation and the LOS in the surgical population. The Kaplan-meier curve showed that the early co-management group had a lower probability of staying longer at the hospital $(p<0.0001)$. This could be a consequence of the improvement of clinical management, resulting in a reduced time to discharge and also a sign of a delayed request of the hospitalist evaluation of chronic and complex patients by the others departments, resulting in a late evaluation of these cases. To our knowledge, this is the first study considering the impact of an early beginning of the comanagement of oncological surgical patients in the LOS.

This study has several limitations. It is a retrospective, single center analysis and it was not adjusted for patients comorbidities and demographic characteristics. The definition of early and late beginning of the co-management as 3 days from admission was arbitrary but the results were similar when we considered it as 2 days. Also, we did not measure the ALOS from both groups before the beginning of the Hospital Medicine Department.

The co-management of cancer surgical patients has progressively increased in number of patients since the Hospital Medicine team creation while the LOS has decreased during this period. There was an association between an early follow up by the hospitalists and a lower LOS. A structured and prospective study with adjustments for comorbidities, demographic characteristics and type of intervention could confirm our retrospective data.

\section{Conflicts of Interest}

The author has no conflicts of interest to declare.

\section{References}

1. Watcher RM (2009) The Hospitalist Model of Care: The fastest growing specialty in Medical History [Internet]. Knol.

2. Watcher RM, Goldman L (1996) The emerging role of "hospitalists" in the American health care system. N Engl J Med 335: 514-517.

3. http://www.hospitalmedicine.org/Web/About_SHM/Hospitalist_ Definition/Web/About_SHM/Industry/Hospital_Medicine_Hospital_ Definition.aspx.

4. Bracey DN, Kiymaz TC, Holst DC, Hamid KS, Plate JF, et al. (2016) Orthopedic-hospitalist co-managed hip fracture service reduces inpatient length of stay. Geriatr Orthop Surg Rehabil 7(4): 171-177.

5. Rohatgi N, Loftus P, Grujic O, Cullen M, Hopkins J, et al. (2016) Surgical comanagement by hospitalists improves patient outcomes: a propensity score analysis. Ann Surg 264(2): 275-282.

6. Rosenberg RE, Ardalan K, Wong W, Patel S, Gold-von Simson G, et al. (2014) Postoperative spinal fusion care in pediatric patients: Comanagement decreases length of stay. Bull Hosp Jt Dis 72(3): 197-203.

7. Tadros RO, Tardiff ML, Faries PL, Stoner M, Png CY, et al. (2017) Vascular surgeon-hospitalist comanagement improves in-hospital mortality at the expense of increased in-hospital cost. J Vasc Surg 65(3): 819-825.

8. Koo D, Goring TN, Saltz LB, Kerpelev M, Kumar CB, et al. (2015) Hospitalists on an inpatient tertiary care oncology teaching service. Oncol Pract 11(2): e114-119.

9. Pucciarelli S, Zorzi M, Gennaro N, Marchegiani F, Barina A, et al. (2018) Relationship between hospital volume and short-term outcomes: a nationwide population-based study including 75,280 rectal cancer surgical procedures. Oncotarget 9(24): 17149-17159.

10. Nassour I, Choti MC, Porembka MR, Yopp AC, Wang SC, et al. (2018) Robotic-assisted versus laparoscopic pancreaticoduodenectomy: oncological outcomes. Surg Endosc 32(6): 2907-2913.

11. Sharma G, Kuo YF, Freeman J, Zhang DD, Goodwin JS (2010) Comanagement of hospitalized surgical patients by medicine physicians in the United States. Arch Intern Med 170(4): 363-368. 
12. de Vries S, Jeffe DB, Pruitt SL, Davidson NO, Schootman M (2014) Patient, hospital, and geographic disparities associated with comanagement during hospitalization for colorectal cancer surgery. J Hosp Med 9(4): 226-231.

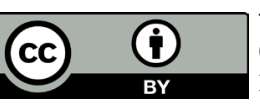

This work is licensed under Creative Commons Attribution 4.0 License DOI: 10.19080/JTMP.2018.03.555611

\section{Your next submission with Juniper Publishers} will reach you the below assets

- Quality Editorial service

- Swift Peer Review

- Reprints availability

- E-prints Service

- Manuscript Podcast for convenient understanding

- Global attainment for your research

- Manuscript accessibility in different formats ( Pdf, E-pub, Full Text, Audio)

- Unceasing customer service

Track the below URL for one-step submission https://juniperpublishers.com/online-submission.php 